Preprint.

Later published: Environmental Science and Pollution Research Vol.5 No.2, pp. 89-93

\title{
Risk Assessment of Conventional Crop Plants in Analogy to Transgenic Plants
}

Helge Torgersen, Institute of Technology Assessment, Austrian Academy of Sciences, Postgasse 7/4, A-1010 Vienna, Austria

Gerhard Soja, Agricultural Research and Biotechnology, Department of Life Sciences, Austrian Research Centre Seibersdorf, A-2444 Seibersdorf, Austria

Ines Janssen, Austrian Ecology Institute, Seidengasse 13, A-1070 Vienna, Austria

Helmut Gaugitsch, Federal Environment Agency, Spittelauer Lände 9, A-1090 Vienna, Austria

Corresponding Author: Dr. Helge Torgersen

\begin{abstract}
The risk assessment of genetically-modified plants pursuant to Annex II B of EU Directive 94/15/EC assumes that it is possible to infer the environmental impacts of a crop plant from its characteristics, so most of Annex II should also be applicable to conventional plants. To test this, we surveyed reports on the ecological impacts of the cultivation of non-transgenic crop plants with novel or improved traits and, in three cases, investigated whether Annex II B would have been adequate to indicate the effects. Such an assessment appears feasible only if the time frame on which ist is based is short, so that long-term effects cannot be assessed. Secondly, the plant must be genetically homogenous which is not always granted, e.g. trees in forest. Thirdly, the cultivation area must be defined. Differences in the behaviour of foreign plants between their original and cultivation habitats may be ecologically relevant and should be assessed. In the (few) cases where direct inference of the observed effects was possible from inherent
\end{abstract}


(few) cases where direct inference of the observed effects was possible from inherent traits, these effects often correlated with poor adaptation to local environmental conditions. The ecological impacts of traits that had been introduced in order to overcome poor adaptation may differ widely according to the way in which the traits are exploited. In practice, the effects of agricultural measures are more important than the effects of gene transfer and invasiveness, although the latter currently play a major role in risk assessment. In the light of these deliberations, a modification of Annex II B of EU Directive 94/15/EC is suggested.

Keywords: Transgenic Plants; Conventional Crop Plants; Environmental Risk Assessment; Gene Transfer and Invasiveness; Agricultural Practice; EU Directive 94/15/EC

\section{Introduction}

The cultivation of crop plants sometimes leads to such side effects as soil erosion, contamination by pesticide residues, gene transfer through cross-breeding or the loss of natural species due to the higher competitiveness of invasive cultivated crops. Whether or not such effects can occur depends largely on certain traits inherent to the plants: reproduction behaviour, various resistance factors and different requirements concerning soil and climate. Although it is widely accepted that transgenic crop plants do not differ fundamentally from conventional plants, and that only the traits matter [1], it is only with genetically-modified plants that the possible impacts are assessed a priori [2]. The EU considers separate regulation to be necessary because, through genetic engineering, fundamentally-new traits can be introduced. In the assessment pursuant to EU Directive 94/15/EC [3], conclusions are drawn with regard to the possible behaviour of the plants and to any effects resulting from the trait introduced. In principle, it should be possible to identify ecological impacts from the cultivation of most crop plants with the help of these criteria. 


\section{Methods}

To test this, we compiled information both from scientific literature and from interviews with experts as to the ecological effects ensuing from the cultivation of eleven selected conventional crop plants (apple, carrot, cocksfoot, maize, potato, oilseed rape, black locust, Norway spruce, sunflower, Jerusalem artichoke, and wheat) with respect to newlybred or specific traits. We assessed which of these effects are relevant in practice, whether it is possible to deduce them from individual traits, and what kinds of secondary effects can be found [4-6].

Although we found it difficult to relate the effects reported to certain traits of the crop plants, some correlations could be established if the time frame assessed was short, the cultivation area defined, and the plant genetically homogenous. However, agricultural practice appeared to be of greater empirical importance with regard to ecologicallyrelevant effects than either invasiveness or gene transfer. Plant-cultivation measures are determined by the needs of the individual culture in interaction with the environment, especially by resistance factors and tolerances. Breeding modifications have led to changes in cultivation conditions and thus had ecological impacts. We concluded that cultivation measures and traits cannot be assessed separately, and that the biological needs fulfilled by any of these measures must be taken into account [7].

We then assessed the questionnaire in Annex II B of Directive 94/15/EC to determine whether it is possible to predict effects previously identified as practically important. In a thought experiment, wheat, maize, and black locust were subjected to risk assessment. To wheat and maize, a special trait was arbitrarily assigned in order to analyse its effects; black locust was assessed as a species.

\section{Results}




\subsection{Wheat}

We investigated a wheat variety with short stalks, a trait common to many modern high-yield varieties.

\subsubsection{The Problem}

Short stalks were a breeding goal because lodging (laying wheat stalks flat) was an important factor for yield losses. Frequently, lodging is due to a fungus infestation; therefore, fungicides are applied. The high nitrogen supply has led to an increase in yield; however, since the ears grow heavier, the stalks lay down more easily. Thus, the yield of long-stalk varieties could not be increased any further unless chemicals were applied to shorten the stalks. Today, varieties with short stalks are available that lower the risk of breaking, avoid "shorteners", and - potentially decrease fungicide use. However, as a consequence, it is possible to increase the nitrogen supply in order to increase the size of the ears, until lodging occurs again. Due to the higher input, the susceptibility for fungus disease and, hence, the use of fungicides may increase again.

\subsubsection{Coverage by Annex II B of EU Directive 94/15/EC}

The appropriate questions of Annex II B are in Sections D and H. Section D deals with modifications that concern interactions with other organisms; Section $\mathrm{H}$, with the ecological effects of these modifications. The pertinent question is D.9 (Potentially significant interaction with nontarget organisms). However, the wording only makes sense if a plant is resistant to a parasite (e.g. by means of a toxin) and if organisms other than the parasite are directly affected. In our case, the shortening of the stalks may be interpreted as a modification of the conditions which the parasite (fungus) meets. Therefore, data on modified conditions for interactions with other organisms appear necessary. In the case of tolerances, possible interactions with the abiotic environment are important and should be indicated as well. Secondly, short stalks may lead to higher input, but this is not linked directly to the trait. Nevertheless, higher input may easily be anticipated. Therefore, possible effects on cultivation measures should be included, with regard to the effects on agricultural input. 


\subsection{Maize}

Maize may be regarded as an "exotic species". The "Exotic Species Model" had considerable influence on the shaping of the EU Directive on deliberate release [8]. The trait assigned was cold tolerance, being of practical ecological relevance [5].

\subsubsection{The Problem}

In Austria, the vegetation period for maize is very short, and the juvenile and maturation phases are problematic. Cultivation requires the soil to remain open for a long time, in order to make up for the initial lack in competitiveness. In predisposed ecosystems, erosion and herbicide problems may occur. With early-maturing varieties or with silage maize, the maturation phase is no longer a limiting factor. Cold-tolerant varieties, on the other hand, allow for a faster juvenile growth and result in an earlier covering of the soil and, hence, in ecological improvements. However, the cultivation area may also be expanded to colder climates, where maize replaces such betteradapted forage plants as clover. Here, the same problems must be expected as is observed in places where the old varieties can be grown. With cold-tolerant varieties, the situation should improve in such places, whereas problems must be expected in new cultivation areas in colder climates.

\subsubsection{Coverage of Annex II B of EU Directive 94/15/EC}

Since the effects might differ considerably according to the ecosystem, the potential to expand the cultivation area is an important information. The pertaining parts of Annex II B are Sections $\mathrm{D}$ and H. However, the potential to expand the cultivation area is not the subject of this questionnaire.

\subsection{Black Locust}

Black locust was chosen as a forest tree where genetic diversity is desirable. Hence there are no specific varieties easily discernible. 


\subsubsection{The Problem}

Due to its ability to regenerate vegetatively, black locust is difficult to remove. With its special root system and its ability for nitrogen fixation, it is highly competitive. Black locust may also be regarded as an "exotic species" and may lead to the loss of indigenous species. However, the genetic basis of black locust is difficult to assess: the variability is high and, consequently, longterm effects are difficult to pinpoint.

\subsubsection{Coverage by Annex II B of EU Directive 94/15/EC}

Annex II B refers to the comparison of an existing variety with a new variety. Therefore, only a description of traits in compliance with Section B (Information Relating to (A) the Recipient or (B) (where appropriate) Parental Plants) was carried out. The "exotic" character is covered by questions B.6 (In the case of plant species not normally grown in the Member States, description of the natural habitat of the plants, including information on natural predators, parasites, competitors and symbionts) and B.7 (Potentially significant interactions of the plant with organisms other than plants in the ecosystem where it is usually grown, including information on toxic effects on humans, animals and other organisms). In B.6, the habitat of the plant and its behaviour are to be described. In our case, it includes references to symbionts (rhizobium), incompatibility with birch and beech, reasons for differing competitiveness, and persistency in the native regions and Europe, etc. In Annex II B, this question applies only to exotic species in the narrower sense, i.e. those that are not found in Europe. Plant species cultivated in a member state are excluded, regardless of their ecological impacts. However, for black locust, such information would be useful; though often regarded as an "exotic species", it does not meet the formal criteria. The limitation to the "natural" habitat leads to a loss of important information. Additionally, in question B.7, the restriction to "non-plant" is too narrow.

\subsection{Proposal for an Amendment of Annex II B of EU Directive 94/15/EC}

In our view, the shortcomings detected may also arise with other plants and are not restricted to the cases analysed. In particular, reference should be paid to altered conditions for the interaction 
with organisms and the environment, to cultivation measures likely to be determined by the plant assessed, to the possible extension of the cultivation area, and to a better understanding of the nature and impacts of an "exotic" crop plant. We propose the following amendments to Annex II B of EU directive 94/15/EC:

\section{Section B}

3. b) (rephrasing) Specific abiotic factors affecting survivability (temperature, water, soil and nutrient needs, stress tolerances).

3. c) (new): Genetic homogeneity, genetic adjustment potential.

5. b) (new): $\quad$ Form of utilisation and cultivation.

6. (rephrasing): In the case of plant species not grown in agriculture and forestry in the Member States, description of the natural habitat of the plant and the ecosystem in which it is to be grown, including information on natural predators, parasites, competitors and symbionts.

7. (rephrasing): In the case of plant species grown in agriculture and forestry in the Member States, potentially significant interaction with the biotic and abiotic environment in the ecosystem in which it is usually grown, and possible changes to these interactions in the ecosystem in which it is to be grown, including information about toxic effects on humans, animals and other organisms.

\section{Section D}

9. (rephrasing): Do any modified conditions result for interaction with other organisms and the abiotic environment?

10.) (new): Does the genetic modification allow, promote or require changes in agricultural practice, including possible expansion of the growing area into other ecosystems? 


\section{Section $\mathbf{H}$}

4. (rephrasing): Possible environmental impact resulting from potential interactions with other organisms and the abiotic environment.

5. (new): $\quad$ Possible environmental impacts resulting from agricultural practice that has been modified due to the new traits, including possible expansion of the ecosystem where it is grown.

\section{Discussion}

\subsection{Agricultural Practice}

A reason for the difficulty of assigning certain effects to different traits may be the way in which we generally perceive crop plants, which creates the basis for our "familiarity" with them: generally, it is performance that is investigated, and not the unintended effects. Hence, in practice, "familiarity" with a certain crop plant refers primarily to agronomic performance and less to environmental impacts. In risk assessment, analogous to the assessment of agronomic performance, it is the short-term effects which are investigated in relatively few individual subjects. It is thus not surprising that it has hardly been possible to relate environmentally-relevant effects to specific traits. Effects could be surveyed only by intensive monitoring during widespread cultivation provided one knows what to look for. For transgenic crops, however, monitoring is normally not provided for, because the licensing procedure for placing crops on the market does not specify any monitoring obligation.

Among those effects where a correlation could be established are the slow juvenile growth of maize leading to erosion danger, and the lack in competitiveness during early growth stages resulting in high herbicide requirements. Such effects are often associated with sub-optimal adaptation to local environmental conditions (e.g. climate) and are usually not specifically bred. Little attention is generally paid to these traits and effects within the scope of current risk assessment. Such environmental effects occur primarily under conditions of intensive agriculture, which are difficult to modify in practice. New breeds with tolerances that could reduce them may actually fail to do so due to maxi- 
mum exploitation of the trait in practice. For example, short-stalk wheat helps to prevent crop failure and the use of fungicides through improved stability - as long as the tendency for lodging does not increase through heavier ears. Hence, the practice that is made possible by a certain trait is obviously more important in terms of environmental impact than the trait itself. Its significance lies in the fact that it allows various practices - those that prevent negative effects, and those that merely shift or even enhance them. The assessment of a trait without considering the associated cultivation method is therefore questionable.

\subsection{Gene Transfer and Invasiveness}

In the OECD study entitled "Safety Considerations for Biotechnology" [2], gene transfer and invasiveness are seen as the main points to consider in a risk assessment of transgenic plants. These events also have been observed occasionally in conventional plants and may be more common than has been hitherto acknowledged. For example, in the case of oilseed rape, it has been shown that genes are transferred rapidly to wild relatives [9]. However, the practical significance of this phenomenon in several cases appears to be fairly low. The negative effects of invasiveness were observed in about one out of 1000 non-indigenous species [10]. The only significant effect due to gene transfer and invasiveness which we could detect in the analysis of "model" plants was the suppression of the crab apple by weedy domestic apples in some very specific habitats [4]. Although the selection of plants may not be entirely representative, the effects of gene transfer seem to be of minor importance in practice, and those of invasiveness are problematic in only few cases. This has led many scientists, companies and regulators to conclusions that today's transgenic crops are inherently safe [11].

Gene transfer also depends on local environment and cultivation conditions. Gene transfer will almost certainly happen somewhere, since transgenic varieties will be cultivated in areas in which cross-breeding partners exist [12]. Their distribution, and hence the frequency of gene transfer, will vary locally. Agricultural practice influences the probability of contact between hybridisation partners depending on the field-edge surface (edge effect). Therefore, it is important whether an agricultural system has larger or 
smaller fields. For example, the small average size of fields in Norway compared with the mean in the EU, and thus the greater probability of cross-breeding and gene transfer was recently mentioned in a Norwegian commentary on an application for placing transgenic oilseed rape on the market (T.H. Nielsen, TMV Oslo, pers. Communication).

Invasiveness is the result of interaction between a (hybrid) species and the ecosystem; it cannot be reasonably assessed by analysing the traits of one (parental) species alone without taking into account the environment. However, this is precisely what is required for placing a crop on the market. Experience with field tests must necessarily refer to only a few (mostly similar) ecosystems. The possibility of invasiveness depends on the removal of volunteers, crop rotation, and the existence of fallow or ruderal sites, among other reasons. Therefore, even if we were to restrict ourselves to the parameters of gene transfer and invasiveness and to assess their probability, agricultural practice cannot be excluded from any analysis.

This was also emphasised in a recent paper describing the rationale for a monitoring experiment with transgenic hybrid oilseed rape [13]. The authors stressed the point that comparisons (the basis of "familiarity") are difficult to make since "little data are available on how non-GM oilseed rape behaves." They criticised that risk assessment has not "considered whether the agronomy of the GM crop has an environmental impact." For example, Glufosinate - which is more effective than current herbicides - may kill a wider spectrum of plants if it drifts into the field margins, hence permitting more volunteer rape to establish itself. Enhanced colonisation “...may thus be due to the changed herbicide regime rather than to characteristics of the GM rape." They conclude that "it is important that assessments of impact are based on comprehensive environmental audits of both the plant and its agronomic management, so that meaningful comparisons can be made with current cropping of non-GM crops." Our results and conclusions fully support such an approach.

\section{Conclusion}


Since there is agreement that it is mainly the phenotypic characteristics (as determinants of agronomical practice) that are significant for defining any possible risk, most of the criteria in Annex II B may also be applied to conventional plants. However,

- conclusions with regard to anticipated effects cannot always be drawn from phenotypic traits with sufficient certainty - although this is a prerequisite for the currently-practised form of risk assessment;

- the significance of gene transfer and invasiveness is much lower in practice than in risk assessment, where ecological impacts of major practical importance are not taken into account because they concern agricultural practice;

- possible differences resulting from different time scales and the cultivation areas are not adequately taken into consideration.

The complex procedure for the risk assessment of transgenic plants may be inadequate with regard to the possible effects to be avoided. In our opinion, there are two solutions:

- In the long term, the introduction of "ecological sustainability" as a breeding goal in terms of a prophylactic environmental protection would be desirable. Definitions being provided, this would allow for more consistent regulations that do not discriminate against transgenic plants.

- In the short term, the shortcomings should be relieved by assessing the possible influence on agricultural practice and amending the text of Annex II B to EU Directive 94/15/EC as indicated. Also, post-marketing monitoring schemes and new ways of modelling realistic agronomic conditions have to be found.

\section{References}

[1] Miller, H. I. (1995): Concepts of Risk Assessment: The "Process versus Product" Controversy Put to the Rest. In: Biotechnology (vol. 12): Legal, Economic and Ethical Dimensions. D. Brauer (ed.) (2nd ed.) Verlag Chemie, Weinheim. FRG. 
[2] OECD (1992): Safety Considerations for Biotechnology. Paris, France.

[3] Directive 94/15/EC from 15. April 1994 for the "First Adaptation of the Directive 90/220/EWG on the Deliberate Release of Genetically Modified Organisms Into the Environment to Technical Progress" (Abl/L 103/20)

[4] Janssen, I., Geissler, S. and Müller, W. (1995): Analyse ökologischer Auswirkungen von land- und forstwirtschaftlichen Nutzpflanzen und eingeführten standortfremden Pflanzen als Basis für die Risikoabschätzung gentechnisch veränderter Pflanzen. Austrian Ecology Institute, Vienna.

[5] Soja, G. and Soja, A.-M. (1995): Analyse ökologischer Auswirkungen von landund forstwirtschaftlichen Nutzpflanzen und eingeführten standortfremden Pflanzen als Basis für die Risikoabschätzung gentechnisch veränderter Pflanzen. Seibersdorf Report OEFZS-A-3419 and 3467, Austrian Research Centre Seibersdorf.

[6] Geburek, T. (1995): Charakteristika der Baumart Fichte (Picea abies (L.) karst.). Eine Zusammenschau von Eigenschaften einer Baumart, welche für die Erstellung eines Kriterienkatalogs zur Risikoabschätzung genetisch manipulierter, langlebiger höherer Pflanzen dienlich sein könnte. Expertise for the Institute for Technology Assessment, Austrian Academy of Sciences, Vienna.

[7] Torgersen, H., Soja, G., Janssen, I., Gaugitsch, H. (1997): Ecological Impacts of Traditional Crop Plants - A Basis for the Assessment of Transgenic Plants?", BioSafety Vol. 3, Paper 1 (BY97002), February 1997 Online Journal, URL http://www.bdt.org.br/bioline/by

[8] Sukopp, U. and Sukopp, H. (1994): Ecological long-time effects of the growing wild of crop plants. WZB papers FS II, 94-304. Science Centre Berlin for Social Science Research, Berlin, FRG.

[9] Mikkelsen, T. R., Andersen, B. and Joergensen, R. B. (1996): The Risk of Crop Transgene Spread. Nature 380, 31. 
[10] U.S. Congress, Office of Technology Assessment (OTA) (1993): Harmful NonIndigenous Species in the United States. OTA-F-565, Washington D.C.

[11] Goy, P. A. and Duesing, J. H. (1996): Assessing the Environmental Impact of Gene Transfer to Wild Relatives. Bio/Technology 14, 39-40.

[12] Kareiva, P., Morris W. and Jacobi, C.M. (1994): Studying and Managing the Risk of Cross-Fertilization between Transgenic Crops and Wild Relatives", Molecular Ecology $3,15-21$.

[13] Sweet, J.B. and Shepperson, R. (1997): Monitoring Commercial Releases of Genetically Modified Oilseed Rape", Proceedings of the X. Colloque International sur la Biologie des Mauvaises Herbes, Dijon, September 1996. 